\title{
Source process of the October 12, 1992 Cairo earthquake
}

\author{
Hesham Mohamed Hussein \\ National Research Institute of Astronomy and Geophysics, Seismology Department, Helwan, Cairo, Egypt
}

\begin{abstract}
Broadband body waves recorded at 12 digital seismic stations worldwide were used to study the source process of the October 12, 1992 Cairo earthquake. To study the source process of this event the $P$ and $S H$ waveforms from IRIS data center were inverted to double couple source using the method Kikuchi and Kanamori (1991) in which the rupture is presented by discrete subevents with various mechanisms. The best solution consists of only one event with a mechanism $270^{\circ} / 47^{\circ} /-123^{\circ}$ (strike/dip/slip), a normal faulting mechanism with small strike slip component. This solution is almost compatible with the previously suggested mechanisms for the same event. This event took place at a depth of $22 \mathrm{~km}$. This depth explains the lack of surface faulting. The seismic moment is $7.2 \times 10^{17} \mathrm{Nm}$ $\left(M_{w}=5.8\right)$ with a source duration of $4 \mathrm{~s}$. The estimated fault length is about $11 \mathrm{~km}$, the derived average dislocation $(D)$ is $0.24 \mathrm{~m}$, the stress drop $(\Delta \sigma)$ is $1.85 \mathrm{MPa}$ and the Orwan stress drop is $0.425 \mathrm{MPa}$.
\end{abstract}

Key words inversion - source process - Cairo earthquake

\section{Introduction}

On October 12, 1992 a violent earthquake took place in Dahshor region, $25 \mathrm{~km} \mathrm{SW}$ of Cairo city $\left(M_{B}=5.8 ; M_{S}=5.4\right)$. This earthquake is called the Cairo earthquake (fig. 1) by the National Research Institute of Astronomy and Geophysics (NRIAG-Egypt). The focal parameters, as reported by NRIAG, were an origin time $13: 09: 56.5$, an epicenter location at $29.77 \mathrm{~N}-$ $31.07 \mathrm{E}$, a depth of $22 \mathrm{~km}$ (NEIC) and a magnitude $M D(\mathrm{HLW})=5.3$. This is the largest earthquake known to have occurred in this seismic

Mailing address: Dr. Hesham Mohamed Hussein, National Research Institute of Astronomy and Geophysics, Seismology Department, P.O. Box 70, Helwan 11421, Cairo, Egypt; e-mail: hesham65@hotmail.com zone since the historical destructive earthquake of August 1848. The main shock was followed by a long aftershock sequence. According to the government announcement 561 people were killed, 12199 were injured and more than 20000 people became homeless. More than 8300 buildings were damaged or destroyed. The total loss was estimated to be 4 bilion U.S. dollars.

Abu el Enean et al. (1997) relocated the hypocenter of the aftershocks which occurred for one year, using the arrival times recorded by a network of portable analog seismographs (fig. 1). Installation of 7 Spregnether MEQ-800 began on October 13, $24 \mathrm{~h}$ after the main shock. All of these stations were equipped with $1 \mathrm{~Hz}$ L4-C vertical seismometers. After nearly one week field seismographs were operated at five sites. On November 3, the other two stations were sited in the epicentral area. In addition to these stations, data were also available from four permanent stations (HLW, SPH, KEG, TAS) at distances up to $220 \mathrm{~km}$ (fig. 2). Hypocentral locations were determined using the 


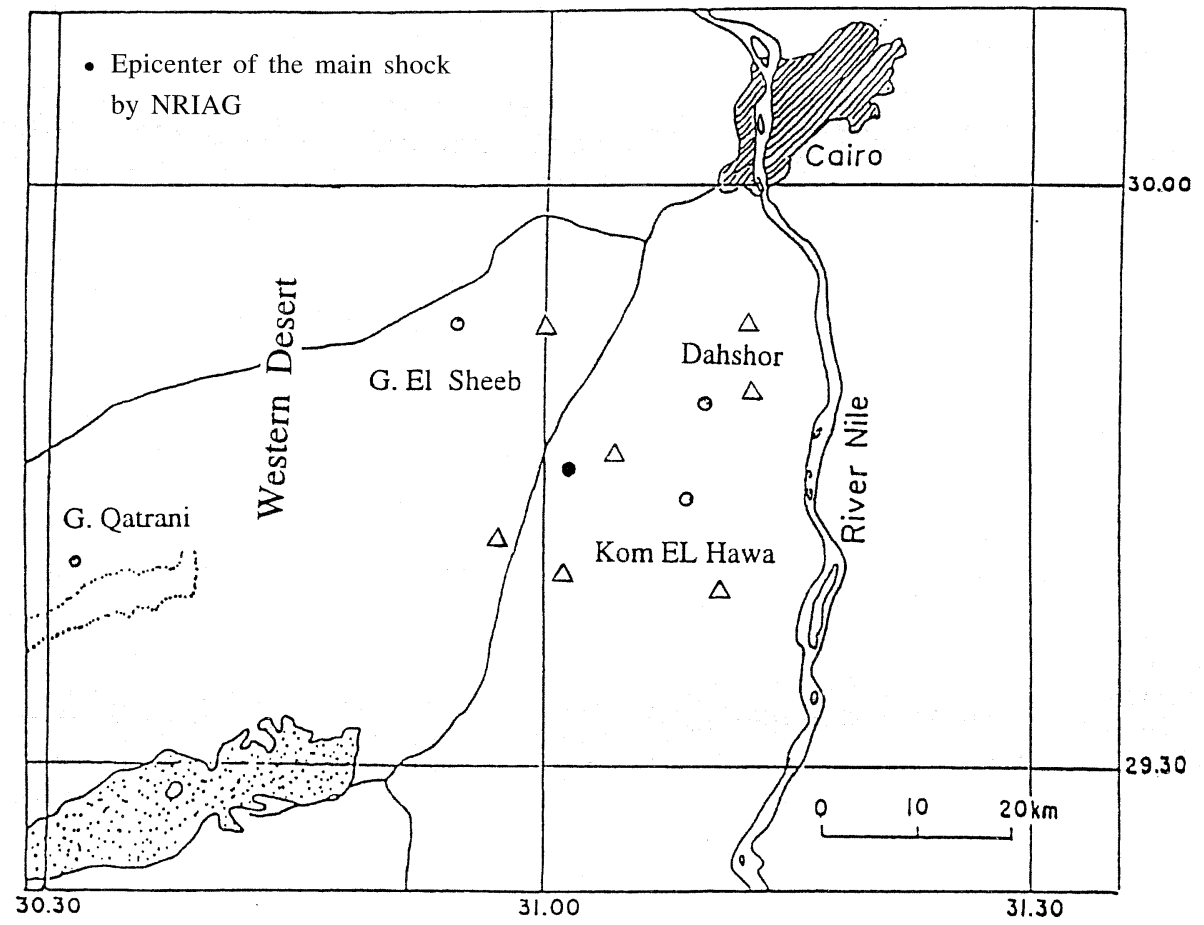

Fig. 1. Epicenter of the Cairo earthquake (solid circle). Open triangles represent the network station locations.

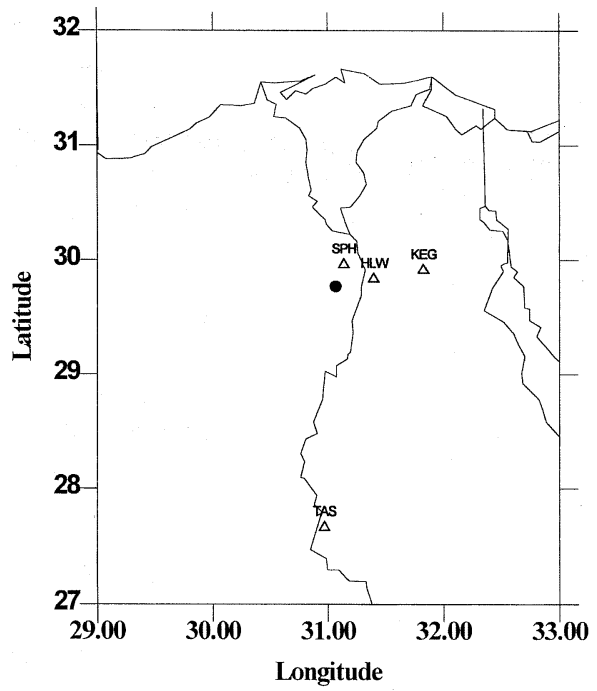

Fig. 2. Locations of the permanent stations.
HYPO71PC program (Lee, 1990). The spatial distribution of the well-located aftershocks appears to form a cluster (fig. 3). The main shock took place at the western edge, outside the cluster. The aftershock activity appears to migrate eastward during the first $24 \mathrm{~h}$ of the sequence. The 3D distribution of the aftershocks (Maamoun et al., 1993) indicates the upward propagation of the aftershocks, which are shallower than the mainshock hypocenter along a plane dipping $50^{\circ}$ to the NE. The main activity is confined between 15 and $23 \mathrm{~km}$ of depth.

The main purpose of this work is to determine the mechanism of this event including fault geometry, fault area, rise time, seismic moment and other related source parameters, using waveform inversion. Determination of these parameters is useful not only for understanding the physics of earthquakes but also 
for estimating the potential hazard associated with stress changes on the faults adjacent to the earthquake (Kanamori et al., 1992). This event is the first in this region for which a fault plane solution is derived. Therefore, this earthquake provides the only clue to the active tectonics of Dahshor region.

\section{Data}

The data set used in this study consists of $P$ and $S H$ body waves recorded by the digital network of the Incorporated Research Institute of Seismology (IRIS) in the epicentral distance range between $30^{\circ}$ and $90^{\circ}$. In this distance range, the waveforms are not contaminated by strong upper mantle or core phases. Fourteen body wave records from 12 stations, including vertical $P$ and horizontal $S H$ components, were used in this study to derive the source process of this earthquakes. The parameters of these stations are given in table I. Deconvolution of the instrumental response was made to obtain broadband displacement seismograph type (Kikuchi and Kanamori, 1986, 1991). The records were bandpassed between $.02 \mathrm{~Hz}$ and $0.5 \mathrm{~Hz}$. This frequency band provides a convenient characterization of the rupture process for the teleseismic source spectrum (Houston, 1990). Figure 4 shows the displacement records of $P$ waves as well as $S H$ waves at several sta-

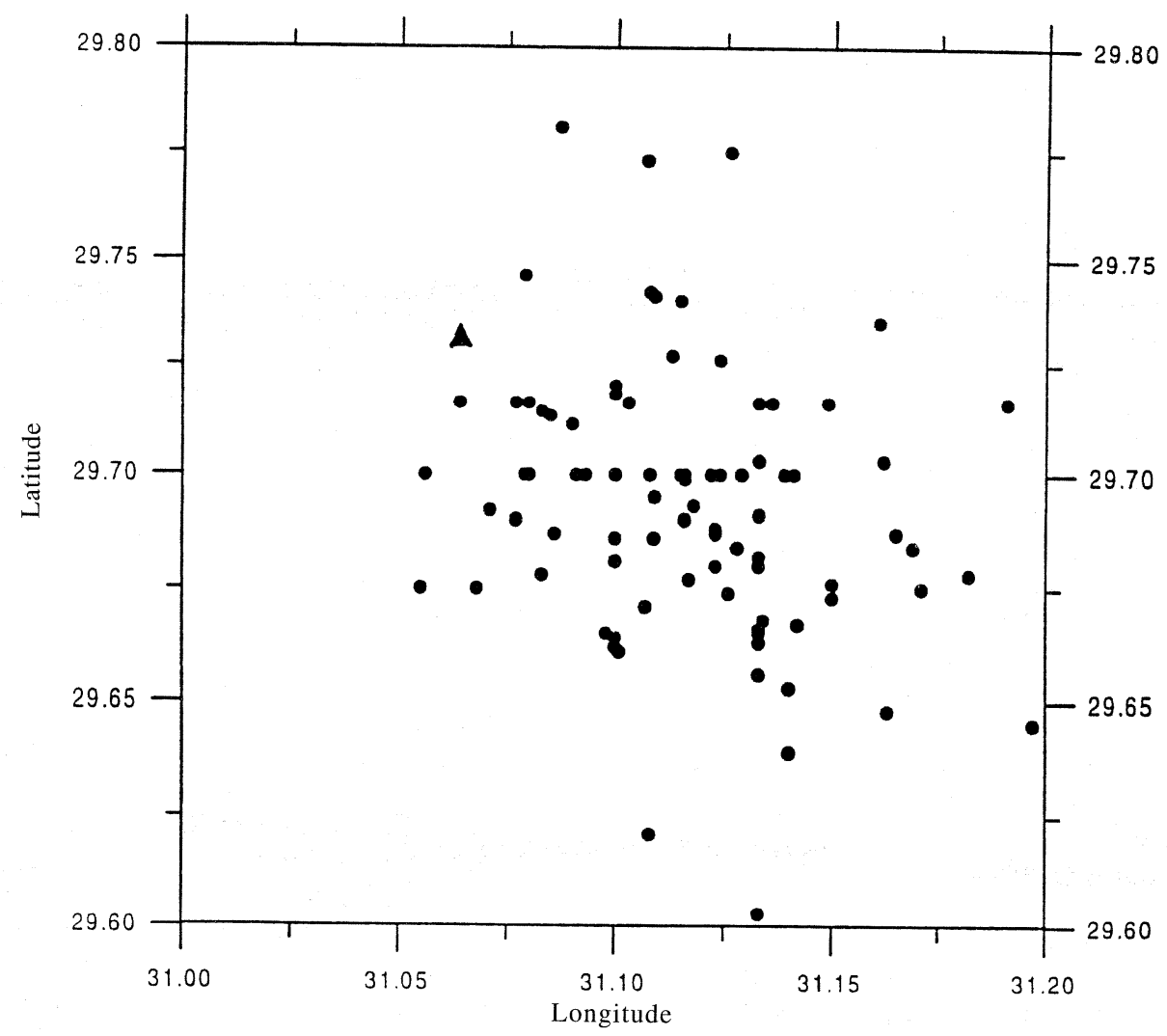

Fig. 3. Epicentral distribution of the aftershocks. The triangle represents the location of the Cairo earthquake mainshock. 
Table I. List of station parameters.

\begin{tabular}{lcccc}
\hline \hline Station & $\begin{array}{c}\text { Azimuth } \\
\text { degree }\end{array}$ & $\begin{array}{c}\text { Back azimuth } \\
\text { degree }\end{array}$ & $\begin{array}{c}\text { Distance } \\
\text { degree }\end{array}$ & Phase \\
\hline YSS & 39.9 & 305.4 & 81.8 & $P$ \\
HIA & 45.1 & 289.5 & 67.10 & $P$ \\
MDJ & 46.7 & 279.3 & 75.20 & $P$ \\
MAJO & 50.4 & 303.0 & 84.90 & $P$ \\
WMQ & 56.1 & 272.10 & 46.50 & $P$ \\
LZH & 63.0 & 286.70 & 60.0 & $P$ \\
LSA & 74.0 & 286.00 & 51.5 & $P, S H$ \\
KMI & 75.2 & 292.00 & 62.8 & $P$ \\
CHTO & 83.3 & 294.3 & 62.0 & $P, S H$ \\
HRV & 312.8 & 59.80 & 78.8 & $P$ \\
CCM & 318.2 & 47.3 & 90.00 & $P$ \\
COL & 359.5 & 1.0 & 85.40 & $P$ \\
\hline
\end{tabular}

tions. The $P$ wave displacement records are almost simple. This suggests that the earthquake's source consisted of a single event. Therefore, the first $50 \mathrm{~s}$ of the data from the onset of the direct $P$ waves and $S H$ waves were windowed for this study. The information contained in this time window is adequate to resolve the source process. The moderate magnitude of this event limited the azimuthal coverage to the NE and NW quadrants. At some stations an inflexion is observed in the first $P$ wave up swing almost $6 \mathrm{~s}$ after the start of the record. This represents the $p P$ depth phase (fig. 4).

The crustal structure of the source region (Marzouk, 1987) used in the calculation of the synthetic waves consists of 3 layers, $32.5 \mathrm{~km}$ thick crust and semi infinite mantle layer. The thickness of the first layer is $2.5 \mathrm{~km}$ with $P$ wave velocity $3.5 \mathrm{~km} / \mathrm{s}$. This layer is underlain by two layers, each $15 \mathrm{~km}$ thick and with average $P$ wave velocities of about 6.0 and $6.35 \mathrm{~km} / \mathrm{s}$ respectively. At the receiver the crustal structure is assumed to be a half space. The $P$ and $S$ waves velocities for the half space are 6.0 and $3.46 \mathrm{~km} / \mathrm{s}$ respectively, with a rock density of $2.7 \mathrm{gm} / \mathrm{cm}^{3}$.

\section{Teleseismic body wave inversion}

Many earthquakes have complex sources involving time-dependent source processes (Strelitz, 1980; Kikuchi and Kanamori, 1986). For example, the fault may rupture in different time periods and the segment of the fault may have varied focal mechanisms, an earthquake may also initiate at shallow depth and then reinitiate at deeper location. The pre-existing plane of weakness, the re-adjustment of the stress field, the heterogeneity of the fault area are among the possible factors which contribute to complicate the source process (Das and Aki, 1977; Kanamori, 1981; Ruff, 1983).

To investigate such details of the rupture process, a time dependent moment tensor inversion technique for teleseismic data (Kikuchi and Kanamori, 1991), was used to resolve the source complexity by matching the waveforms and extraction of the source parameters. In this method the rupture is represented by a sequence of subevents (point sources) distributed on the fault plane. The subevent mechanisms were determined from the data and allowed to vary during the rupture. The subevents were succes- 


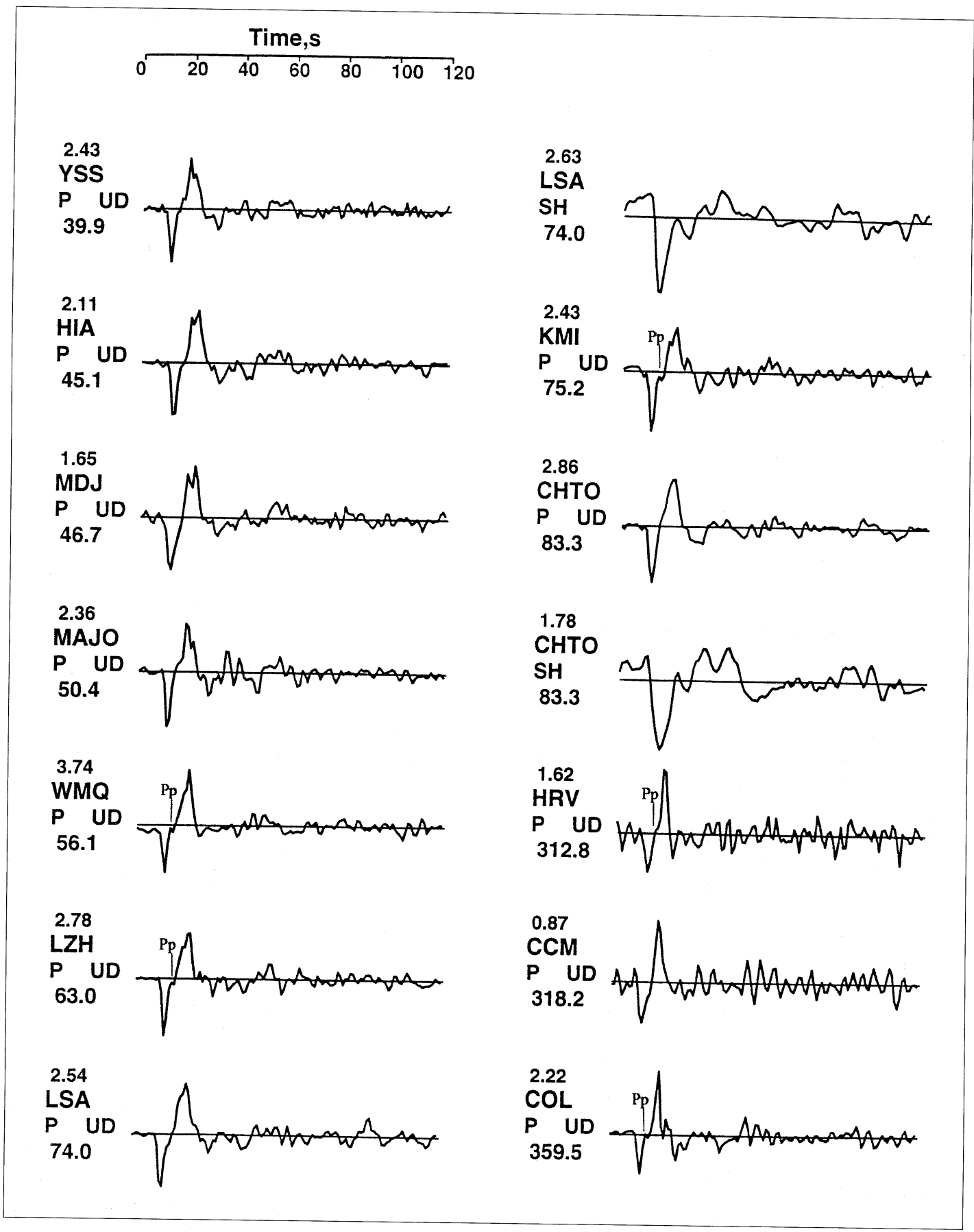

Fig. 4. Body waves recorded by some IRIS stations for the Cairo earthquake. 
sively determined by minimizing the squared difference between the observed and synthetic waveforms with a grid search over all the values of source parameter $P . P$ is a parameter that collectively represents the onset time, the location, and any other attributes to the source along the strike and depth. The first step of inversion was the calculation of Green's function for the six elements of the moment tensor at four discrete depths (18, 20, 22 and $24 \mathrm{~km})$ beneath the epicenter, assuming a single subevent. The focal depth lies within this depth range. For $Q$ attenuation a Futterman (1962) operator $t^{*}$ (ratio of travel time to average $Q$ ) of $1 \mathrm{~s}$ was used for $P$ waves and $4 \mathrm{~s}$ for $S$ waves (Helmberger, 1983). This $Q$ filter was convolved with a triangle source time function with a rise time $\tau_{1}$ of $2 \mathrm{~s}$ and a source duration $\tau_{2}$ of $4 \mathrm{~s}$. Consequently, the seismograms were simultaneously inverted to double couple single subevent in the least square sense for the source model parameter, assuming no change in the mechanism during rupture. The inversion process was carried out over the four discrete depths. The depth yielding the minimum residual was taken as the depth of the source.

For this event a point source model provided more or less equal fits to most of the waveforms. This means that a single source is sufficient to describe the source process of this earthquake. The $P$ wave records as well as the $S H$ waves, at different stations (fig. 4) also reflected a smooth rupture without any prominent subevents. The fit of data for the point source model is shown in fig. 5a-c. The final residual waveform error is 0.2628 . Observed directivity due to rupture propagation is not clear. The best matching double couple has a strike of $270^{\circ}$, a dip of $47^{\circ}$ and a rake of $-123^{\circ}$, normal faulting mechanism with small strike slip component. Moreover, inversion was done using this solution as a fixed mechanism and the results indicate a good fit to the data with a final residual waveform error equal to 0.2631 . A slight change in the parameters of the fault plane caused an increase in the residual waveform error. The results of the two different inversions produce synthetics that fit the observed data equally well. At least 4 previously determined fault plane solutions exist for 1992
Cairo earthquakes (HRVD Moment tensor solution (Dziewonski et al., 1993; El Hadidy, 1993; Maamoun et al., 1993; Abu Elenean et al., 1997). All these solutions preferred nearly normal fault mechanism with some strike slip component although they do not completely agree on the fault orientation. Table II summarizes the parameters of these solutions.

For simplicity, the above solutions will hereafter be referred to as CMT (HRVD solution), E93 (El Hadidy, 1993), M93 (Maamoun et al., 1993) and A93 (Abu Elenean et al., 1997). Three of them (CMT, M93, A93) imply normal faulting mechanisms with small strike slip components on a roughly WNW-ESE striking plane. E93 preferred normal faulting mechanism with some strike slip component along a roughly E-W striking plane. This solution was obtained through body wave inversion using both $P$ and $\mathrm{SH}$ waves, with a smaller data set. M93 and A93 were determined from the observations of the $P$ wave first motions from WWSSN stations. The focal depth of $22 \mathrm{~km} \pm 1 \mathrm{~km}$ obtained in this study is in agreement with the depths determined from CMT and E93. The released seismic moment is $7.2 \times 10^{17} \mathrm{Nm}$, which corresponds to moment magnitude of 5.8 with source duration of $4 \mathrm{~s}$. The source duration of $4 \mathrm{~s}$ is also consistent with the other duration estimates (CMT, E93). Seismic moment estimates from spectral analysis of teleseismic $P$ body waves (Al Ibiary, 1993; Hussein et al., 1998), spectral magnitude calculations (Hussein et al., 1998), body wave inversion (El Hadidy, 1993) and moment tensor analysis (HRVD solution) range from $5.6 \times 10^{17}$ to $9.97 \times 10^{17} \mathrm{Nm}$. Considering the different methods, the seismic moment obtained in the present study is in the range of those previously calculated (table III).

Assuming a circular fault model, the fault area of this event can be estimated using the relation of Fukao and Kikuchi (1987)

$$
S=\pi\left(V_{r} \tau / 2\right)^{2}
$$

where $V_{r}$ is the rupture velocity, typically $(0.7-$ $0.9) V_{s} \cdot V_{s}$ is the shear wave velocity. $\tau$ represents the rupture duration. $V_{r} \tau / 2$ term represents the source radius (a). The estimated source radius of this event is $5.6 \mathrm{~km}$. Therefore 


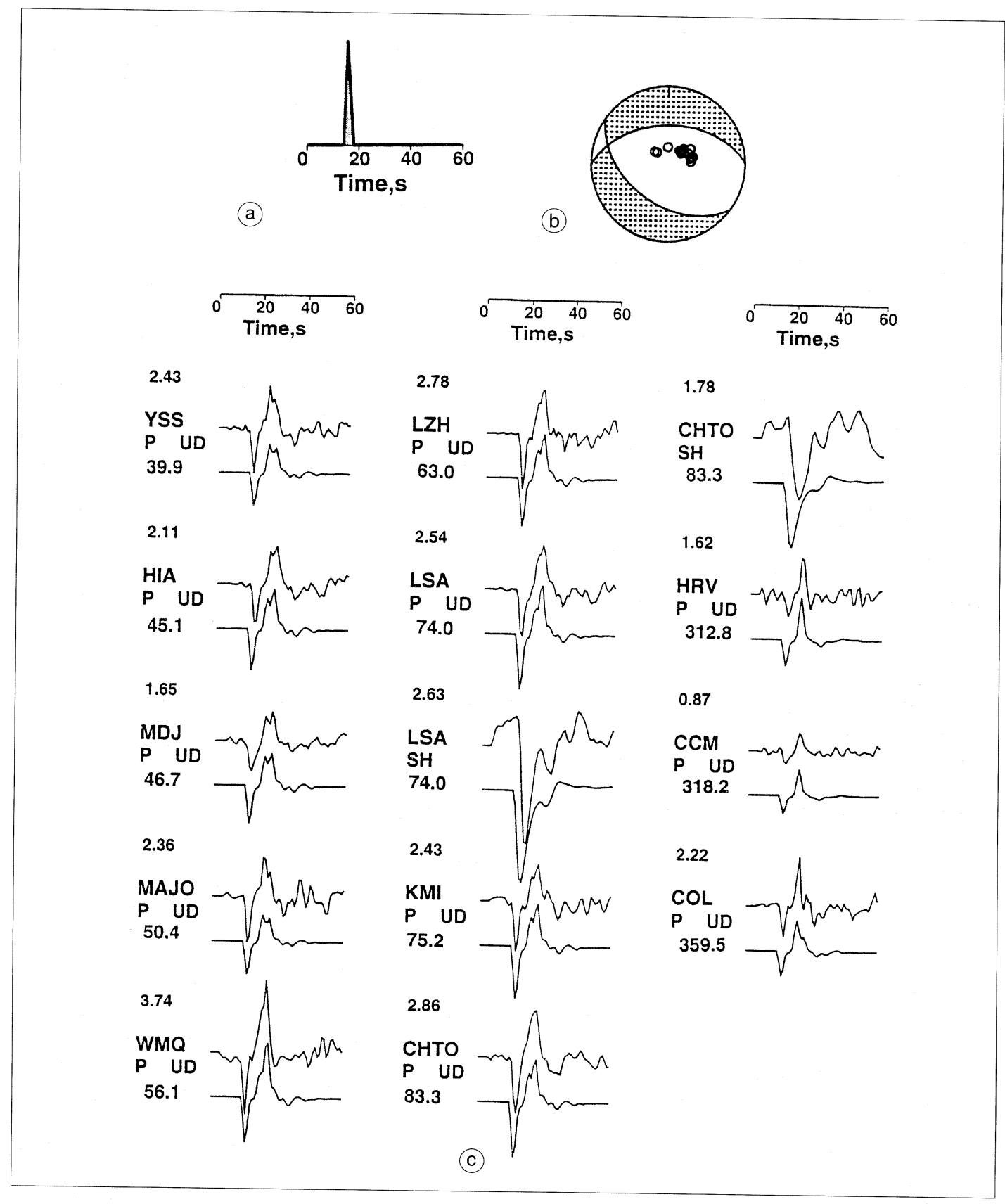

Fig. 5a-c. Results of the inversion with a double couple source. a) Seismic moment release as a function of time; b) mechanism diagram of the best fit double couple point source; c) observed and theoretical $P$ and $S H$ waveforms. The numbers in the upper and lower left indicate peak to peak amplitude in microns of the observed records and the azimuth respectively. 
Table II. Source models derived by different authors.

\begin{tabular}{lccccc}
\hline \hline Reference & $\begin{array}{c}\text { Strike } \\
\text { degree }\end{array}$ & $\begin{array}{c}\text { Dip } \\
\text { degree }\end{array}$ & $\begin{array}{c}\text { Rake } \\
\text { degree }\end{array}$ & $\begin{array}{c}\text { Source duration } \\
\text { s }\end{array}$ & $\begin{array}{c}\text { Depth } \\
\text { km }\end{array}$ \\
\hline CMT & 297 & 49.0 & -103.0 & 4 & 22 \\
E93 & 262 & 54.0 & -144.0 & 4 & 23 \\
M93 & 289 & 49.5 & -138.7 & & \\
A93 & 282 & 57.0 & -136.0 & & \\
This study & 275 & 48.0 & -122.0 & 4 & 22 \\
\hline
\end{tabular}

Table III. Source parameters of the 1992 Cairo earthquake estimated by different authors.

\begin{tabular}{lcccccc}
\hline \hline \multicolumn{1}{c}{ Reference } & $\begin{array}{c}\text { Al Ibiary } \\
(1993)\end{array}$ & $\begin{array}{c}\text { El Hadidy } \\
(1993)\end{array}$ & $\begin{array}{c}\text { Hussein } \\
\text { et al. }(1998) \\
\text { Spectral } \\
\text { analysis }\end{array}$ & $\begin{array}{c}\text { Hussein } \\
\text { et al. }(1998) \\
\text { Spectra } \\
\text { magnitude }\end{array}$ & $\begin{array}{c}\text { HRVD } \\
\text { Dziewonski } \\
\text { et al. }(1993)\end{array}$ & $\begin{array}{c}\text { This } \\
\text { study }\end{array}$ \\
\hline Moment $(\mathrm{Nm})$ & $9.1 \mathrm{E} 17$ & $6.99 \mathrm{E} 17$ & $9.77 \mathrm{E} 17$ & $9.97 \mathrm{E} 17$ & $5.6 \mathrm{E} 17$ & $7.2 \mathrm{E} 17$ \\
Stress drop $(\mathrm{MPa})$ & 0.648 & 2.30 & 0.51 & 0.76 & & 1.85 \\
Radius $(\mathrm{km})$ & 8.5 & 4.5 & 9.5 & 6.9 & & 5.5 \\
Area $\left(\mathrm{km}^{2}\right)$ & 227 & 81.0 & 283.0 & 149.49 & & 99.0 \\
Dislocation $(\mathrm{m})$ & 0.13 & 0.22 & 0.12 & 0.22 & & 0.245 \\
\hline
\end{tabular}

the length of the fault will be about $11 \mathrm{~km}$ $(L=2 \mathrm{a})$. This length is nearly the same length as the aftershock zone. The estimated fault area is $99 \mathrm{~km}^{2}$.

Using the aftershock area $S$, we can obtain the average stress drop $(\Delta \sigma)$ following Fukao and Kikuchi (1987)

$$
\Delta \sigma=2.5 M_{0} / S^{1.5}
$$

where $M_{0}$ is the seismic moment. The stress drop corresponding to this event is $1.8 \mathrm{MPa}$.

According to the slip dislocation theory of faulting (Aki, 1966), the average dislocation (D) can be estimated from

$$
D=M_{0} / \mu S
$$

were $\mu$ is the rigidity $\left(3 \times 10^{10} \mathrm{~N} / \mathrm{m}^{2}\right)$. The obtained value is $0.24 \mathrm{~m}$.

The dislocation velocity can be determined from the dislocation-time history following Kanamori (1972)

$$
D^{0}=D / \tau / 2 .
$$

The value obtained in this study is $0.12 \mathrm{~m} / \mathrm{s}$ for a rise time of $2 \mathrm{~s}$.

The above estimated source parameters differ from those calculated previously (table III). As seen in table III, the source parameters are not exactly compatible with each other. The cause of the discrepancy between these parameters might be that source parameters (e.g., stress drop) depend strongly on the actually faulted area. The faulted areas obtained in the earlier works were estimated from spectral corner frequency of telesismic $P$ waves (Al Ibiary, 1993; Hussein et al., 1998), aftershocks (El Hadidy, 1993) and the corner frequency corresponding to maximum magnitude spectrum (Hussein et al., 1998) and are therefore different.

The estimated value of $M_{0} / \tau^{3}=1.125 \times 10^{23}$ is the same costant value obtained by Ekström et al. (1992) for shallow continental earthquakes with $M_{w}=5 \sim 7 . \tau$ represents the pulse width of the source time function. An Orwan stress drop can be obtained from the seismicaly radiated energy $E_{s}$ and the moment $M_{0}$. The Orwan stress drop (Orwan, 1960) is defined as 
follows:

$$
\Delta \sigma=2 \mu E_{s} / M_{0}
$$

assuming that the final stress $\left(\sigma_{2}\right)$ is equal dynamic frictional stress $\left(\sigma_{f}\right)$ on the fault. Therefore, the Orwan stress drop can be obtained from seismic moment $\left(M_{0}\right)$ and energy $\left(E_{s}\right)$. The calculation of the stress drop by this method has advantages over some other methods because it does not require the estimation of the rupture area from the aftershock distribution or from azimuthal variation of the source time process or spectral corner frequency (Houston, 1990). This quantity depends on the energy over the entire faulting process. The estimated seismic energy from the source spectrum of the $P$ wave first motion by NEIC is $5.1 \times 10^{12} \mathrm{Nm}$. The Orwan stress for Cairo earthquakes is equal to $0.425 \mathrm{MPa}$. This value is lower than the static stress drop estimated before in this work. This may be due to deviation from Orowan's condition $\left(\sigma_{2}=\sigma_{f}\right)$ or due to short fault length.

\section{Conclusions}

Modeling of body waves recorded at teleseismic distances has shown that the 1992 Cairo earthquake was a normal faulting event with small strike slip component on a roughly east west striking plane. This earthquakes had a shallow crustal focal depth of $22 \mathrm{~km}$. Observable directivity is not clear due to short fault length. The estimated fault length associated with the main shock is $11 \mathrm{~km}$. The cluster of aftershocks indicates nearly the same fault length with unilateral eastward rupture propagation. The seismic moment released along the fault is $7.2 \times 10^{17} \mathrm{Nm}$. This seismic moment corresponds to a moment magnitude of 5.8. The stress drop associated with a fault area of $99 \mathrm{~km}^{2}$ is equal to $1.85 \mathrm{MPa}$. The average displacement is $0.24 \mathrm{~m}$ and the dislocation velocity is $0.12 \mathrm{~m} / \mathrm{s}$. The Orwan stress of Cairo earthquakes is $0.425 \mathrm{MPa}$ which is smaller than static stress drop obtained by the other methods. This is due to the deviation from Orwan's condition $\left(\sigma_{2}=\sigma_{f}\right)$. The value of $M_{0} / \tau^{3}$ obtained in the present study is $1.125 \times 10^{23}$. This value is a typical value of continental shallow earthquakes.

\section{Acknowledgements}

This work was carried out at the Meteorological Research Institute (MRI) Tsukuba, Japan. My sincere thanks go to Dr. Y. Yoshida of Meteorological Research Institute (MRI), Tsukuba, Japan for his assistance and valuable suggestions. I would like to express my deep thanks to Dr. Suetsugu of International Institute of Seismology and Earthquake Engineering (IISEE), Building Research Institute (BRI), Ministry of Construction, Tsukuba, Japan, for his constructive suggestions and support. I am also very grateful to the staff members of the International Institute of Seismology and Earthquake Engineering (IISEE), Building Research Institute (BRI), Ministry of Construction, Tsukuba, Japan, for their kind help. I am very tankful to the Japan International Cooperation Agency (JCA) for providing the necessary funding required for this study. I would like to express my deep thanks to three anonymous reviewers for their valuable comments.

\section{REFERENCES}

Abu Elenean, K.M., H.M. Hussein, A.S. Abu El Ata and E.M. IBRAHIM (1997): A seimological aspects of Cairo earthquakes (personal communication).

AKI, K. (1966): Generation and propagation of $G$ waves from the Niigata earthquake at June 16, 1964, Bull. Earthquake Res. Inst., Tokyo Univ., 44, 73-88.

AL IBIARY, M. (1993): Geophysical contribution on October 12th, 1992 earthquakes, Geophysical Research Team, Report, Ain Shames Univ. Cairo, Egypt.

DAS, S. and K. AKI (1977). Fault plane with barriers: a versatile earthquakes model, J. Geophys. Res., 82, 5628-5669.

DzIEWONSKI, A.M., G. EKSTRÖM and M.P. SALGNIK (1993): Centroid moment tensor solution for OctoberDecember, 1992, Phys. Earth Planet. Inter., 80, 89-103.

EKström, G., R.S. STEIN, J.P. EATON and D. EBERHARTPHILLIPS (1992): Seismicity and geometry of a $110 \mathrm{~km}$ long blind thrust fault. The 1985 Kettleman Hills California Earthquake, J. Geophys. Res., 97, 48434864.

EL HADIDY, S. (1993): Source process of the 1992 Cairo, Egypt earthquakes using far field seismo- 
gram, Report for the Course of Seismology 19921993, IISEE, Japan.

FUKAO, Y. and M. KIKUCHI (1987): Source retrieval for mantle earthquakes by iterative deconvolution of long-period P-waves, Tectonophysics, 144, 249-269.

FUTTERMAN, W.I. (1962): Dispersive body wave, J. Geophys. Res., 67, 5279-5291.

HELMBERGER, D.V. (1983): Theory and application of synthetic seismograms, in Earthquake: Observation, Theory and Interpretation (Società Italiana di Fisica, Bologna, Italy), 174-222.

IOUSTON, H. (1990): Broadband source spectrum, seismic energy and stress drop of the 1989 Macquarie ridge earthquakes, Geophys. Res. Lett., 17, 1021-1024.

Hussein, H.M., K.M. ABu ElEnEAN, E.M. IBRAHIM and A.S. ABU EL ATA (1998): Spectral magnitudes and source parameters for recent damaging earthquakes in Egypt, Bull. IISEE., 32, 1-24.

KANAMORI, H. (1972): Determination of effective tectonic stress associated with earthquake faulting: the Tottori earthquake of 1943, Phys. Earth Planet. Inter., 5, 426-434.

KANAMORI, H. (1981): The nature of seismicity patterns before large earthquakes, in Earthquake Prediction: an International Review, edited by D.W. SIMPSON and P.G. RICHARDS, Am. Geophys. Un., Washington, D.C., 1-19.

Kanamori, H., H.K. Thio, D. Dreger and E. HAUKSSON (1992): Initial investigation of the Landers, Califor- nia earthquake of 28 July 1992 using TERRscope, Geophys. Res. Lett., 19, 2267-2270.

KIKUCHI, M. and H. KANAMORI (1986): Inversion of complex body waves - II, Phys. Earth. Planet. Inter., 43, 205-222.

KIKUCHI, M. and H. KANAMORI (1991): Inversion of complex body waves - III, Bull. Seismol. Soc. Am., 79, 670-689.

LEE, W.H.K. (1990): HYPO71PC Program, IASPEI Software Library, vol. 1.

Maamoun, M.E., A. Meghaed, A. Hussin and L. MarZOUK (1993): Preliminary Studies on the Dahshour Earhquake, National Research Institute of Astronomy, Cairo, Egypt, abstract.

MARZOUK, I. (1987): Crustal structure studies in Egypt, Ph.D. Thesis, Amburg University, Germany.

ORWAN, E. (1960): Mechanism of seismic faulting, Geol. Soc. Am. Mem., 79, 323-345.

RUFF, L.J. (1983): Fault asperities inferred from seismic body waves, in Proceedings of the International School of Physics «Enrico Fermi», edited by $\mathrm{H}$. KANAMORI and E. BOSCHI (North-Holland Publication Co., Amsterdam), vol. 55, 251-276.

STRELITZ, R.A. (1980): The fate of the downgoing slab: a study of the moment tensors body waves of complex deep focus earthquakes, Phys. Earth Planet. Inter., 21, 83-96.

(received January 7, 1999; accepted June 18, 1999) 